\title{
Dimensões argumentativas e interacionais da Linguística Textual em ambientes digitais
}

\author{
Mayara Arruda MARTINS (D) \\ Universidade Federal do Ceará (UFC)
}

\section{RESUMO}

Esta resenha se propõe a apresentar os conceitos fundamentais discutidos na live intitulada Argumentação e interação em Linguística Textual. A partir de interfaces entre a Linguística Textual e outras abordagens científicas, aspectos como texto, gênero, interação e modalidades argumentativas foram discutidos, em convergência com os novos modos de argumentar em contextos digitais. Apoiadas em autores como Adam (2019), Amossy (2017), Paveau (2015) e Charaudeau (2015), as debatedoras da mesa redonda conseguiram associar os modos de argumentar e de interagir em contextos digitais a critérios como o plano de texto e o contrato de comunicação. Desse modo, a discussão empreendida pelas professoras durante a mesa

EDITADO POR Raquel Freitag

REVISADO POR Mariza Brito redonda envolveu aspectos argumentativos, discursivos e interacionais, enfatizando a importância de se trabalhar com uma interdisciplinaridade focada nos atuais estudos em Linguística Textual.

\section{ABSTRACT}

This review presents some fundamental concepts discussed in the live session entitled Argumentation and interaction in Textual Linguistics. From interfaces between Textual Linguistics and other scientific approaches, aspects, such as text, genre, interaction, and argumentative modalities, were discussed, in the convergence to the new modes of argumentation in digital contexts. Supported by authors, such as Adam (2019), Amossy (2017), Paveau (2015), and Charaudeau (2015), the participants of this roundtable managed to associate the modes of argumentation and interaction in digital contexts to criteria as text plan and communicative contract. Thus, the discussion 


\section{REVISTA DA ABRALIN}

undertaken by the professors during the roundtable involved argumentative, discursive, and interactional aspects, emphasizing the importance of working with an interdisciplinarity focused on the current studies in Textual Linguistics.

PALAVRAS-CHAVE

Texto. Argumentação. Interação.

KEYWORDS

Text. Argumentation. Interaction.

As lives promovidas pela Abralin - Associação Brasileira de Linguística - surgem como resistência e conforto aos pesquisadores de Linguística. De um lado, resistência por utilizar os recursos virtuais como meio para propagar contribuições científicas em um momento em que a ciência, sobretudo as Humanidades, vê-se ameaçada. De outro, conforto por utilizar esses mesmos recursos, que têm sido usados para diminuir distâncias em vários aspectos, a fim de aproximar pesquisadores e demais interessados das diversas áreas dos estudos linguísticos e de contribuir para a formação acadêmica dessas pessoas, de forma compromissada.

Os estudos do texto têm relevância na academia, no ensino e nas práticas sociais. Por isso, a atualização das pesquisas acadêmicas sobre os aspectos fundamentais da área, como seus conceitos básicos, seus critérios de análise e as interfaces possíveis com outras áreas do conhecimento, reflete-se diretamente nas práticas sociais e vice-versa. Assim, os diferentes modos de interagir, como os que surgem com o aumento da frequência de uso da internet, fazem com que surjam também novos modos de argumentar.

A mesa redonda "Argumentação e interação em Linguística Textual" (doravante LT), moderada pela Profa. Dra. Mariza Angélica Paiva Brito (UNILAB/FUNCAP), teve como convidadas três linguistas da área, que se organizaram na seguinte ordem de apresentação, formando um ambiente organizado e complementar aos olhos e aos ouvidos daqueles que as acompanhavam, através dos slides e de suas importantes falas.

Abrindo a mesa redonda, refletimos sobre a fala interdisciplinar da Profa. Dra. Mônica Magalhães Cavalcante (UFC/CNPq); em seguida, acompanhamos a apresentação focada e prática da Profa. Dra. Ana Lúcia Tinoco Cabral (USP/Profletras; IP-PUC-SP); e, por último, assistimos à exposição inovadora da Profa. Dra. Maria Eduarda Giering (UNISINOS/FAPERGS). A seguir, são destacadas algumas das discussões empreendidas pelas professoras durante suas apresentações.

A LT deve a nomes como Marcuschi e Koch os estudos empreendidos por essa área até hoje. E foi regada a muita emoção que a live começou, pois na data de acontecimento da live seria o aniversário de Marcuschi e era o aniversário de morte de Koch, como bem lembrou a professora Mônica 


\section{REVISTA DA ABRALIN}

Cavalcante. As primeiras contribuições dessa área já versavam sobre os critérios de análise investigados hoje, como a coerência, a referenciação, a argumentação, entre outros. No entanto, os estudos científicos em determinada área devem acompanhar o ritmo das práticas relacionadas a ela. Por esse motivo, os modos de interagir, de argumentar e de investigar cada uma dessas evidências também se modificaram.

Desse modo, sem jamais esquecer o compromisso de agir de modo coerente ao que pretende investigar, isto é, analisando os textos à luz dos seus critérios, a LT hoje se vale de interfaces com outras áreas da Linguística para abarcar a relação texto-discurso que emerge nas mais diversas interações. Para isso, outros aportes teóricos se unem, tais como: a Teoria Dialógica do Discurso de Bakhtin, a Teoria da Argumentação no Discurso de Amossy e a Teoria Semiolinguística de Charaudeau.

O conceito de texto (ver mais em Cavalcante et al, 2019), principal objeto de análise da LT, se aproxima do conceito bakhtiniano de enunciado (tal como entendido por Brait, 2016), como evento único e concreto, que está em constante diálogo com outros textos, sempre situado em um contexto sócio-histórico. Essas foram algumas das características do conceito de texto contempladas na fala da professora Mônica.

Situados nesse contexto, os sujeitos interagem e assumem papéis sociais que variam de acordo com o gênero, com a orientação argumentativa que querem sustentar, e, sempre, em relação ao outro. Assim, no circuito comunicativo, é fundamental compreender os papéis sociais que são desempenhados na relação entre sujeitos dentro do quadro interacional e argumentativo, em que ambos assumem vários posicionamentos discursivos em sociedade e procuram desenvolver estratégias de influência sobre o outro. Essas estratégias de influência incidem não somente sobre o interlocutor direto, mas também sobre participantes indiretos: o terceiro.

De acordo com Amossy, o terceiro é aquele que não tem direito à voz, mas, nas interações polêmicas, por exemplo, é sobre ele que recaem as mais diversas estratégias de persuasão. Desse modo, a dimensão argumentativa do texto consiste nessas estratégias negociadas entre locutor e interlocutor (e terceiro) e podem se evidenciar de diversas maneiras, como através de modalidades argumentativas, processos referenciais, apelos intertextuais, entre outros recursos.

Esses recursos de que os sujeitos se valem dependerão das diferentes maneiras de interagir, de agir no mundo, de se relacionar com o outro. Por esse motivo, interagir e argumentar são atividades humanas intrinsecamente interligadas.

Os modos de interagir e de argumentar foram modificados pelas inúmeras possibilidades que os recursos digitais oferecem, como bem destacou a professora Ana Lúcia Tinoco Cabral. Suas análises, voltadas para gêneros que se adaptaram aos ambientes digitais, focaram em aspectos relacionados à mudança no plano de texto, conceito apresentado por Adam (2019), que se complexifica com todas essas possibilidades quando nos inserimos nesse mundo tecnológico. As modificações no plano de texto se evidenciam, sobretudo, como um importante recurso do qual o locutor se vale para conseguir incorporar as novas formas de interação e de argumentação. 


\section{REVISTA DA ABRALIN}

A escolha dos arranjos textuais feitos por esse locutor não garante, no entanto, que suas intenções serão alcançadas. Há sempre efeitos possíveis, projetados pelo locutor em um diálogo com o outro - ainda que pressuposto - mas nunca garantidos, como destaca Charaudeau (2015).

O aspecto dual no processo de leitura e interação em ambientes digitais tem sido discussão importante nos estudos de produção e compreensão de textos nesses ambientes. Se, por um lado, o plano de texto e os modos de interagir se tornam mais complexos, por outro, as indicações hipertextuais simplificam a compreensão de sentidos por parte do leitor, pois tornam acessíveis as informações complementares sobre o tema, em uma rede infinita na internet.

$\mathrm{O}$ advento do uso da internet e esses modos de interação possibilitaram mais facilidade para o diálogo entre os actantes do circuito comunicativo, que podem conversar entre si, em comentários, por exemplo, com o autor do post, etc., ao mesmo tempo em que se inserem em diversas interações possíveis numa rede de interações sobrepostas.

Mais centrada na interação do que na argumentação, a professora Maria Eduarda Giering refletiu sobre os modos como os critérios definitórios da textualidade podem ser afetados (ou necessariamente modificados) devido aos recursos e aos ambientes digitais, valendo-se de textos presentes na obra Faire Texte (Adam e Phillipe, 2015).

A presença do conceito de textos digitais nativos, isto é, textos que surgem e se desenvolvem em ambientes digitais e apresentam características como plurissemioticidade e deslinearização, tornou a apresentação da professora instigante, visto que o caráter inovador de tal conceito nos leva a refletir sobre a hipertextualidade sempre presente nessas interações e sobre a necessidade de alterar os critérios de análise para conseguir abarcar tais processos interativos. Por isso, a professora retomou Paveau (2015) ao abordar os recursos tecnológicos que fundamentam essas interações em rede.

Essas interações se encontram unidas em um domínio tecnodiscursivo, dentro do qual essas práticas linguageiras e interacionais estão inseridas, estejam elas disponíveis on-line ou off-line. Esse domínio tecnodiscursivo possibilita a criação de gêneros completamente dependentes desse meio digital. Por isso, as pesquisas voltadas para esses textos digitais nativos necessitam não somente do conhecimento e do olhar crítico do analista, como também pressupõem a inserção dele no ambiente em que os textos emergem.

As interações em ambientes digitais modificam não somente o modo de interagir e de argumentar em ambientes digitais. Elas fazem surgir novas categorias relacionadas à escrita e à leitura, como é o caso do conceito de escrileitor. Os textos relacionam enunciados potencialmente relacionados uns aos outros e, através de uma grande rede que se constrói a partir da hipertextualidade, cabe ao escrileitor decidir, por exemplo, o percurso da leitura que lhe for mais agradável. Ele, portanto, opera escolhas, quase sempre simplesmente clicáveis, para construir a rede de sentidos do texto. Desse modo, o leitor se torna ainda mais ativo, uma vez que tem ainda mais independência para incorporar conteúdos complementares à leitura. O exercício de escrita e leitura, portanto, ganha um caráter ainda mais colaborativo com as diversas possibilidades que o contexto digital oferece. 


\section{REVISTA DA ABRALIN}

Assim, os elementos que definem a própria textualidade precisam se ajustar aos novos modos de fazer texto, que geram os textos digitais nativos e trazem, junto a eles, a imensa complexidade em analisá-los à luz dos critérios aplicados atualmente.

Muitas são as inovações que a modificação nas práticas sociais trazem aos estudos do texto: aumentam as possibilidades de interação através de novas tecnologias, levam os sujeitos a buscarem novos meios para tentar influenciar o outro (até mesmo - ou principalmente - o terceiro, sempre silenciado), diversificam os modos de ler, escrever, entre outras atividades.

O desafio, agora, que os pesquisadores em LT enfrentam é redefinir categorias para abarcar essas diversas interações que surgem com as novas tecnologias. Por esse motivo, a discussão empreendida na mesa Argumentação e Interação em Linguística Textual se configura como uma importante ferramenta para os pesquisadores dos estudos da linguagem de modo geral, pois apresenta de modo sucinto e aprofundado as relações mais recentemente investigadas na área.

\section{REFERÊNCIAS}

ADAM, J. M. Textos: tipos e protótipos. Trad. Monica Magalhães Cavalcante et al. São Paulo, Contexto, 2019.

ADAM, J. M.; PHILIPPE, G. Continuité et textualité. In. ADAM, J.-M. (org.). Faire Texte. Frontières Textuelles et Opérations de textualisation. Paris: Presses Universitaires de Franché-Comté, 2015. p. 35-80.

ARGUMENTAÇÃO e interação em Linguística Textual. Mesa redonda debatida por Mônica Magalhães Cavalcante, Ana Lúcia Tinoco Cabral e Maria Eduarda Giering, sob mediação de Mariza Angélica Paiva Brito, 2020.1 vídeo (2h 27min 05s). Publicado pelo canal da Associação Brasileira de Linguística. Disponível em:

https://www.youtube.com/watch?v=oBcqw7LXclk\&t=1118s. Acesso em: 15 mai 2020.

AMOSSY, R. Apologia da polemica. Trad. Mônica Magalhães Cavalcante et al. São Paulo: Contexto, 2017.

BRAIT, B. O texto nas reflexões do Círculo e de Bakhtin. In: BATISTA, R.de O. O texto e seus conceitos. São Paulo: Parábola Editorial, 2016. p.13-30.

CAVALCANTE et al. O texto e suas propriedades: definindo perspectivas de análise. Revista (Con)Textos Linguísticos, v. 13, n. 25, 2019, p. 25-39.

CHARAUDEAU, P. La maelstrom de l'interdiscours. In: SOULAGES, J.-C. (Org.). L'analyse de discours - sa place dans la sciences du langage et de la communication. (Homage à Patrick Charaudeau). Renns: Press Universitaires de Rennes, 2015.

PAVEAU, M.-A. En naviguant en écrivant. Réflexions sur les textualités numériques. In: ADAM, J.-M. (org.). Faire Texte. Frontières Textuelles et Opérations de textualisation. Paris: Presses Universitaires de Franché-Comté, 2015, p. $337-353$. 